\title{
Dipole Reversal in Bacteriorhodopsin and Separation of Dipole Components
}

\author{
Guangyu Wang and Dietmar Porschke* \\ Max Planck Institut für Biophysikalische Chemie, 37077 Göttingen, Germany \\ Received: November 20, 2002; In Final Form: February 26, 2003
}

\begin{abstract}
The electrostatics of purple membranes has been analyzed by measurements of the electric dichroism in dc and ac fields in a broad $\mathrm{pH}$ range. The dc data are mainly used to characterize the permanent dipole, whereas the ac data serve as control for changes of global structure and of the induced dipole. At $\mathrm{pH}$ values from 8 to 3.5 , the dc dichroism is negative at low field strengths and turns to positive values at higher field strengths, in qualitative agreement with the orientation function for disks having a permanent dipole moment perpendicular to the plane and an induced dipole moment in the plane. The minimum value of the dichroism, $\xi_{\min }^{\mathrm{dc}}$, indicates the permanent dipole and shows a complex dependence on the $\mathrm{pH}$ but does not approach zero at any $\mathrm{pH}$ between 3.5 and 8 , which would be expected for a simple reversal of the permanent dipole. However, the dependence of $\xi_{\min }^{\mathrm{dc}}$ on $\mathrm{pH}$ shows a $\lambda$ point at $\mathrm{pH} 4.9$, which reflects reversal of the dipole. Fitting of the stationary dichroism for $E \leq 12 \mathrm{kV} \mathrm{m}^{-1}$ to the orientation function shows a decrease of the permanent dipole $\mu$ in the $\mathrm{pH}$ range 5 to about $50 \%$ of the value found at $\mathrm{pH}$ 7. In the same $\mathrm{pH}$ range, the limit dichroism, $\xi_{\infty}^{\mathrm{dc}}$, derived from dc data also decreases to about $50 \%$ of the value at $\mathrm{pH} 7$, whereas parallel measurements of the ac dichroism show almost constant $\xi_{\infty}^{\mathrm{ac}}$ values. The combined observations indicate reversal of the permanent dipole, changes of disk bending, and the existence of a fluctuating dipole moment, probably resulting from bending fluctuations. Reversal of the dipole moment at $\mathrm{pH} 4.9$ is confirmed by combined $\mathrm{pH}$ and field jump experiments. The direction of the dipole is reverted in the same $\mathrm{pH}$ range as the direction of stationary $\mathrm{pH}$ changes upon illumination, indicating an important function of the dipole for vectorial proton transfer. Comparison of experimental data with simple calculations of the protein dipole from the crystal structure indicates the existence of a large dipole component, which is directed opposite to the protein dipole at $\mathrm{pH} 7$ and is probably due to a nonsymmetric distribution of charges on lipid residues. The results indicate a high degree of compensation in the electric asymmetry, which seems to be necessary for stability of purple membranes.
\end{abstract}

\section{Introduction}

Bacteriorhodopsin (BR) is the most actively studied ion transport protein and is considered to be a paradigm of membrane proteins in general..$^{1-4}$ The reaction cycle of bacteriorhodopsin has been studied by many different spectroscopic techniques. Measurements in the visible range of wavelengths were essential for identification of reaction intermediates and for determination of kinetic parameters. Additional information on charge motions during the photocycle was obtained by photoelectric measurements. Combination of optical and electric measurements should be useful for an assignment of both electric and optical parameters for given states of the reaction cycle because electric parameters for given reactions states, defined by their optical parameters, can be used to deduce changes in the charge distribution. A combined set of optical and electric parameters can be obtained by "molecular electrooptical" measurements. These measurements have been used to characterize the electric moment of bacteriorhodopsin in its standard state. ${ }^{5-15}$

Vectorial transport of protons by bacteriorhodopsin is controlled by a combination of different effects: light absorption induces a large $\mathrm{p} K$ change of the Schiff base and, thus, triggers a chain of proton-transfer reactions associated with changes in

* To whom correspondence should be addressed. E-mail: dpoersc@ gwdg.de. the protein structure. Changes of protein structure seem to be essential for the "relay" system, which directs the protons toward the extracellular side. Because the relay system is triggered by a $\mathrm{p} K$ change inside the protein, $\mathrm{pH}$-dependent changes of the protein structure are of interest for understanding of the biological function of bacteriorhodopsin. A remarkable $\mathrm{pH}$ dependence has been found by a combination of electrooptical and photoelectric measurements, which indicated a $\mathrm{pH}$-dependent reversal of the permanent dipole moment of bacteriorhodop$\sin .8,14$ We tried to characterize the proton-induced reversal of the dipole moment by measurements of the electric dichroism. The electric dichroism measured in the permanent dipole regime is expected to be zero at the $\mathrm{pH}$ at which the dipole direction reverts. However, the experimental data show a more complex $\mathrm{pH}$ dependence, which indicates a combination of different contributions to the permanent dipole.

\section{Materials and Methods}

Purple membrane was isolated from Halobacterium salinarum S9 using standard procedures. ${ }^{16}$ Before measurements, the membrane suspensions were extensively dialyzed against standard $\mathrm{pH}$ buffers and were sonicated in a Bransonic 220 for 3 min to break down aggregates. The following buffers were used: $1 \mathrm{mM} \mathrm{NaClO}, 1 \mathrm{mM}$ sodium acetate, and $0.2 \mathrm{mM}$ $\mathrm{CaClO}_{4}$ at $\mathrm{pH}<5.5 ; 1 \mathrm{mM} \mathrm{NaClO}, 1 \mathrm{mM}$ cacodylate, and $0.2 \mathrm{mM} \mathrm{CaClO}_{4}$ at $\mathrm{pH} 5.5-7 ; 1 \mathrm{mM} \mathrm{NaClO}, 1 \mathrm{mM}$ tris- 
(hydroxymethyl)aminomethane, and $0.2 \mathrm{mM} \mathrm{CaClO}_{4}$ at $\mathrm{pH}$ 7-8. Solutions of acetic acid or $\mathrm{NaOH}$ were added for adjustment of $\mathrm{pH}$ values; the conductivity of the solutions was constant within $\pm 20 \%$.

The electric dichroism was measured at $545 \mathrm{~nm}$ and $20^{\circ} \mathrm{C}$ using an instrument described by Porschke. ${ }^{15}$ Electric field pulses were generated by an arbitrary waveform generator (Tektronix AWG 5105) together with an amplifier (Fluke $5205 \mathrm{~A})$. The ac pulses were in the frequency range of $2-10$ $\mathrm{kHz}$. The pulses were applied to the samples in a cuvette with $1 \mathrm{~cm}$ optical path length and with an insert machined from Teflon holding platinum electrodes at a distance of $4.8 \mathrm{~mm}$. The absorbance at $545 \mathrm{~nm}$ was in the range between 0.1 and 0.15 . Usually the plane of polarization was adjusted parallel to the field vector. To maintain the light-adapted state of BR, samples were exposed to the light of a $100 \mathrm{~W}$ lamp; the illumination was interrupted for about $10-15 \mathrm{~s}$ before each measurement to ensure the complete return of BR molecules to the ground state of the photocycle. Complete light adaptation of BR was monitored by determining the ratio of absorbances at 590 and $540 \mathrm{~nm}$. This ratio is about 1.04 and 0.85 for lightand dark-adapted bacteriorhodopsin, respectively. All measurements above $\mathrm{pH} 7$ were performed under $\mathrm{N}_{2}$ flow to avoid $\mathrm{pH}$ drift. Sufficiently long electric field pulses were applied to ensure complete adjustment of the stationary state of orientation. Stationary values of the dichroism were calculated from the stationary change of light intensity using the standard equation

$$
\xi=\frac{\Delta A_{\|}-\Delta A_{\perp}}{\bar{A}}=\frac{1.5 \Delta A_{\|}}{\bar{A}}
$$

where $\Delta A_{\|}$and $\Delta A_{\perp}$ are the field-induced absorbance changes determined by light polarized parallel and perpendicular to the field vector, respectively. $\bar{A}$ is the absorbance in the absence of an external electric field. Measurements of $\bar{A}$ before and after exposure of the samples to electric field pulses proved to be identical within $\pm 1 \%$, except for samples at $\mathrm{pH} \leq 3.5$. Because the dichroism is measured in the present investigation both for $\mathrm{dc}$ and ac pulses, the nature of the dichroism values, $\xi^{\mathrm{dc}}$ and $\xi^{\text {acc }}$, is always indicated by the superscripts dc and ac, respectively.

pH and Electric Field Jump. Combined application of an electric field jump and a $\mathrm{pH}$ jump to a given solution requires a special instrument that allows independent initiation of the jumps. The construction of this instrument will be described elsewhere (Porschke, in preparation). The $\mathrm{pH}$ jump was generated by irradiation of a light pulse to activate a photoreaction. $o$-Nitrobenzaldehyde was used as a photoreactive compound liberating protons upon irradiation at wavelengths in the range between 300 and $350 \mathrm{~nm}$. Control measurements using bromocresol green as $\mathrm{pH}$ indicator in a nonbuffered solution demonstrated a $\mathrm{pH}$ jump from 5.6 to 4.6 with an exponential time constant of $40 \mathrm{~ms}$.

\section{Results}

DC Dichroism. The stationary dichroism, $\xi^{\mathrm{dc}}$, of bacteriorhodopsin measured under dc pulses shows a characteristic dependence on the electric field strength $E$, giving negative $\xi^{\mathrm{dc}}$ values up to a limit field strength $E_{\mathrm{L}}$ and a reversal to positive $\xi^{\mathrm{dc}}$ values at $E \geq E_{\mathrm{L}}$. At neutral $\mathrm{pH}$, the limit field strength is $E_{\mathrm{L}} \approx 30 \mathrm{kV} \mathrm{m}^{-1}$. The form of this dependence is modified by changes of the $\mathrm{pH}$. As shown in Figure 1, a decrease of the $\mathrm{pH}$ from $\sim 7$ to $\sim 5.6$ leads to more negative $\xi^{\text {dc }}$ values before a further $\mathrm{pH}$ decrease to $\sim 4.9$ induces a clear reduction of the

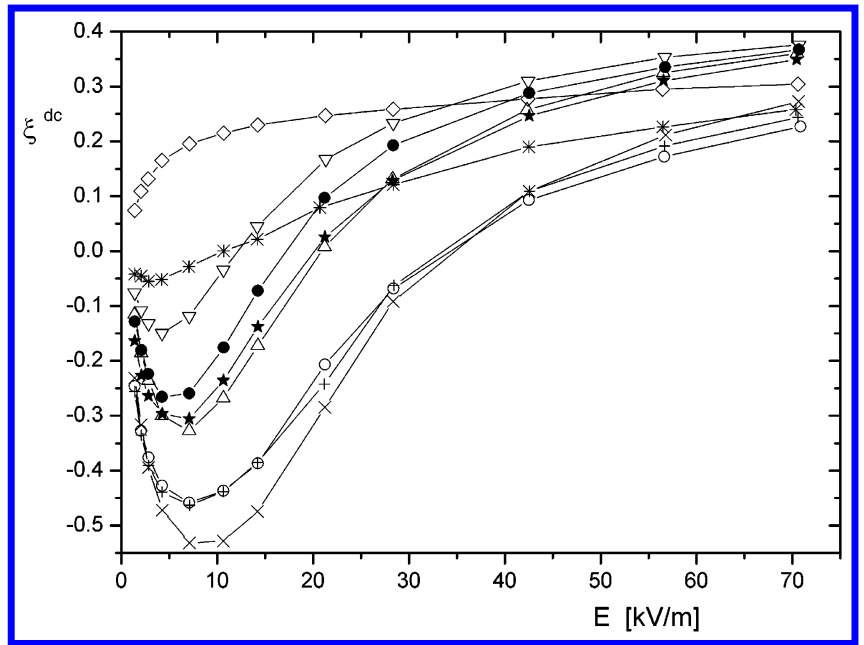

Figure 1. Reduced electric dichroism, $\xi^{\mathrm{dc}}$, of bacteriorhodopsin as a function of the electric field strength, $E$, at different $\mathrm{pH}$ values: $(+)$

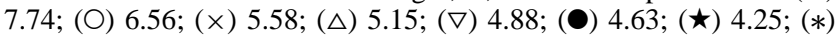
$3.70 ; \diamond) 3.42$. The lines connecting the data points are shown to guide the eye and do not represent any fitted function. Experimental conditions were $20{ }^{\circ} \mathrm{C}, 1 \mathrm{mM} \mathrm{NaClO}, 200 \mu \mathrm{M} \mathrm{CaClO}_{4}$, and $1 \mathrm{mM}$ Tris, cacodylate, or acetate in the different $\mathrm{pH}$ ranges (see Materials and Methods).

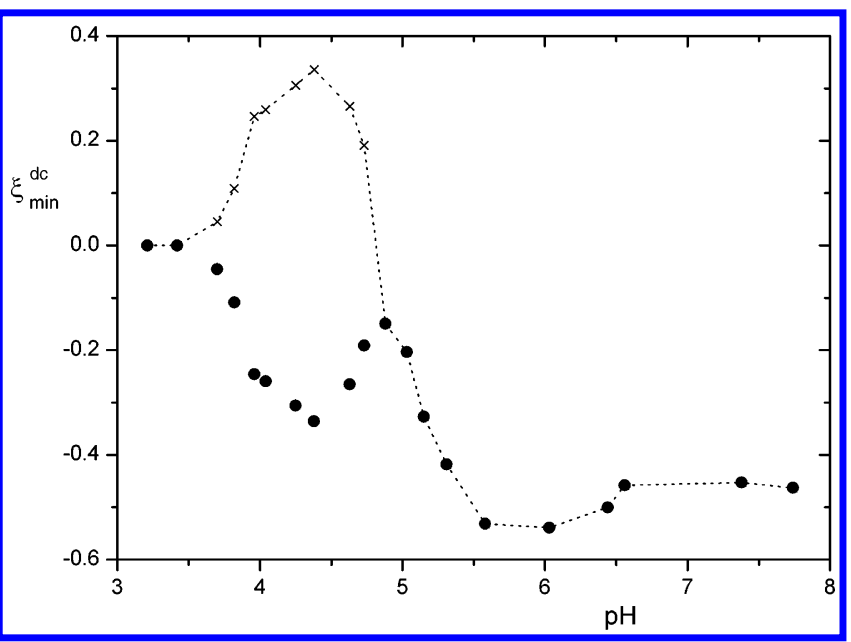

Figure 2. Minimal dichroism, $\xi_{\min }^{\mathrm{dc}}(\bullet)$, as a function of the $\mathrm{pH}$. $\xi_{\min }^{\mathrm{dc}}$ data measured at $\mathrm{pH} \leq 4.8$ are also presented with inverted sign, marked by $\times$. The $\mathrm{pH}$ dependence resulting from inversion is indicated by the dashed line $\left(20{ }^{\circ} \mathrm{C}, 1 \mathrm{mM} \mathrm{NaClO}{ }_{4}, 200 \mu \mathrm{M} \mathrm{CaClO}_{4}\right.$, and $1 \mathrm{mM}$ Tris, cacodylate, or acetate in the different $\mathrm{pH}$ ranges; see Materials and Methods).

$\xi^{\mathrm{dc}}$ minimum. At $\mathrm{pH}<4.9$, the $\xi^{\mathrm{dc}}$ minimum is extended again, followed by a reduction, until finally the minimum disappears at $\mathrm{pH}<3.5$. The rather complex $\mathrm{pH}$ dependence of the $\xi^{\mathrm{dc}}$ value at the minimum, $\xi_{\min }^{\mathrm{dc}}$, is shown in Figure 2 in more detail. At $\mathrm{pH}=4.9$, the function $\xi_{\min }^{\mathrm{dc}}=f(\mathrm{pH})$ has a clear maximum, which seems to be a point of inflection as well and looks like a $\lambda$ point. However, measurements in the $\mathrm{pH}$ range close to 4.9 never showed an approach of the $\xi_{\mathrm{min}}^{\mathrm{dc}}$ value to zero, which should be expected for a simple form of dipole reversal. Mostafa et al. ${ }^{14}$ reported a reversal of the permanent dipole moment for wild-type bacteriorhodopsin at $\mathrm{pH} 5.2$, slightly above the $\mathrm{pH}$ at the $\lambda$ point in Figure 2. These authors used a buffer without added bivalent ions, and thus, their transitions are somewhat shifted on the $\mathrm{pH}$ scale.

The $\xi_{\min }^{\mathrm{dc}}$ value goes to zero at $\mathrm{pH}$ values $<3.5$. However, in this range there is no indication for a reversal of the dipole. Furthermore, it is well-known that bacteriorhodopsin undergoes 


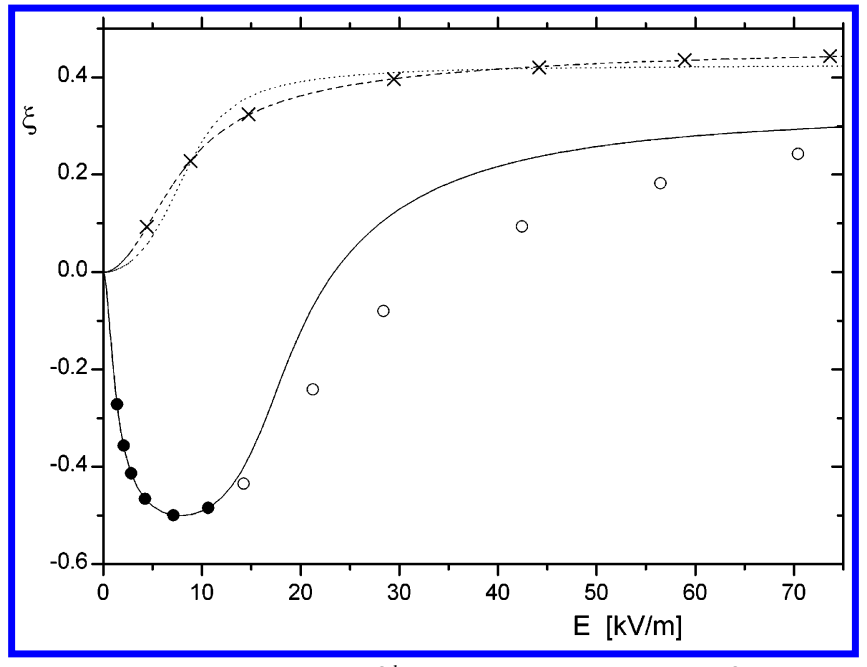

Figure 3. The dc dichroism, $\xi^{\mathrm{dc}}(\mathbf{\bullet}, \bigcirc)$, and ac dichroism, $\xi^{\mathrm{ac}}(\times)$, of bacteriorhodopsin as a function of the electric field strength, $E$. The continuous line represents a least-squares fit of the dc dichroism at low field (๑) by the orientation function for disks developed by Shah ${ }^{17}$ having a permanent dipole $\mu$ perpendicular to the plane and a polarizability $\alpha$ in the plane $\left(\mu=11.6 \times 10^{-24} \mathrm{C} \mathrm{m} ; \alpha=8.68 \times\right.$ $\left.10^{-28} \mathrm{C} \mathrm{m}^{2} \mathrm{~V}^{-1} ; \xi_{\infty}^{\mathrm{dc}}=0.33\right)$. The dc dichroism at high field $(\mathrm{O})$ was not included in the fit. The dotted line represents a least-squares fit of the ac dichroism by the orientation function of $\mathrm{Shah}^{17}$ with the permanent dipole moment $\mu=0$; the dashed line represents a leastsquares fit of the ac dichroism by an orientation function for disks having a polarizability $\alpha$ in the plane, which is saturated at a field strength $E_{\mathrm{s}}\left(\alpha=3.77 \times 10^{-28} \mathrm{C} \mathrm{m}^{2} \mathrm{~V}^{-1} ; E_{\mathrm{s}}=6.3 \mathrm{kV} \mathrm{m}^{-1} ; \xi_{\infty}^{\mathrm{ac}}=\right.$ $0.475 ; 20{ }^{\circ} \mathrm{C}, 1 \mathrm{mM} \mathrm{NaClO}{ }_{4}, 200 \mu \mathrm{M} \mathrm{CaClO}_{4}$, and $1 \mathrm{mM}$ cacodylate, $\mathrm{pH} 6.5)$.

a transition from its "purple" form to the "blue" form at $\mathrm{pH} \leq$ 3.5 for salt concentrations $\geq 100 \mathrm{mM}$. Thus, a $\xi_{\min }^{\mathrm{dc}}$ value zero seems to be characteristic of the blue form of bacteriorhodopsin. Measurements of the absorbance spectrum as a function of the $\mathrm{pH}$ under the same conditions as the present dichroism measurements demonstrate that the center of the purple to blue transition is at $\mathrm{pH} 3.4$ (data not shown).

Because of the special dependence of $\xi_{\min }^{\mathrm{dc}}$ on the $\mathrm{pH}$ in the range around $\mathrm{pH} \mathrm{4.9}$, it is likely that the direction of the dipole is reverted at $\mathrm{pH} 4.9$, although $\xi_{\min }^{\mathrm{dc}}$ does not approach zero. Reversal of the dipole moment clearly does not imply reversal of the sign of the dichroism. However, changing the sign of $\xi_{\min }^{\mathrm{dc}}$ at the inflection point results in a function, $\xi_{\min }^{\mathrm{dc}}=f(\mathrm{pH})$, which looks much more like a standard titration curve than the original function (cf. Figure 2), strongly suggesting inversion of the permanent dipole at the $\mathrm{pH}$ of the inflection point.

The general dependence of the dichroism on the electric field strength, with a minimum in the stationary dichroism and a reversal of its sign at higher field strengths, is consistent with the orientation function for disks having a permanent dipole moment in the direction perpendicular to the plane and an induced dipole moment in the direction parallel to the plane. ${ }^{17}$ However, least-squares fitting demonstrates that experimental data obtained in the range of field strengths up to $70 \mathrm{kV} \mathrm{m}^{-1}$ clearly deviate from the model function. The experimental data can be fitted at a satisfactory accuracy, when these data are restricted to the range of electric field strengths $E<12 \mathrm{kV}$ $\mathrm{m}^{-1}$ (Figure 3). The deviations observed at $E>12 \mathrm{kV} \mathrm{m}^{-1}$ may be due to different effects, including field-induced reactions discussed previously. ${ }^{15,18,19}$

Fitting of the stationary dichroism at low field strengths to the orientation function provides the permanent dipole moment $\mu$ and the limit dichroism $\xi_{\infty}^{\mathrm{dc}}$ as a function of the $\mathrm{pH}$ (Figure

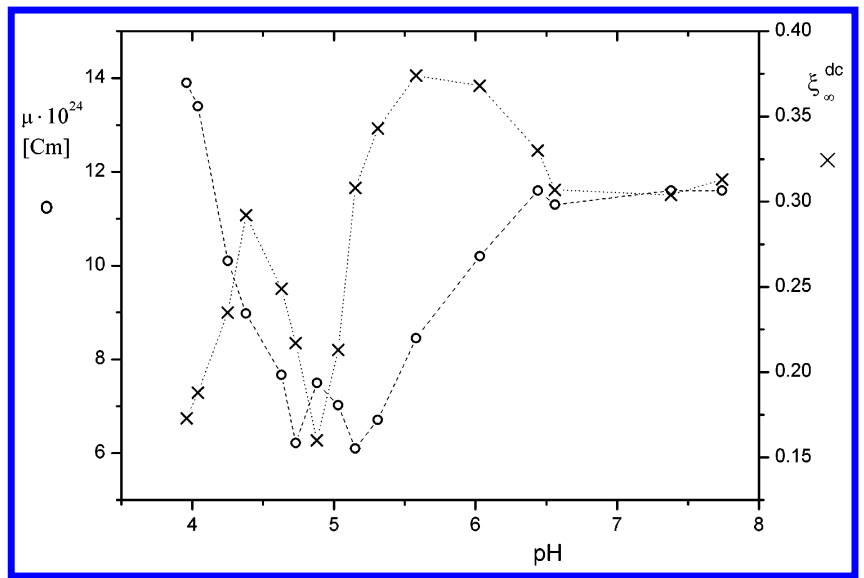

Figure 4. Permanent dipole moment, $\mu$ (left scale; $\bigcirc,---$ ), and limiting value of the dichroism, $\xi_{\infty}^{\mathrm{dc}}$ (right scale; $\times, \cdots$ ), of bacteriorhodopsin disks as a function of the $\mathrm{pH}$ value $\left(20^{\circ} \mathrm{C}, 1 \mathrm{mM} \mathrm{NaClO}{ }_{4}\right.$, $200 \mu \mathrm{M} \mathrm{CaClO}_{4}$, and $1 \mathrm{mM}$ Tris, cacodylate, or acetate in the different $\mathrm{pH}$ ranges; see Materials and Methods).

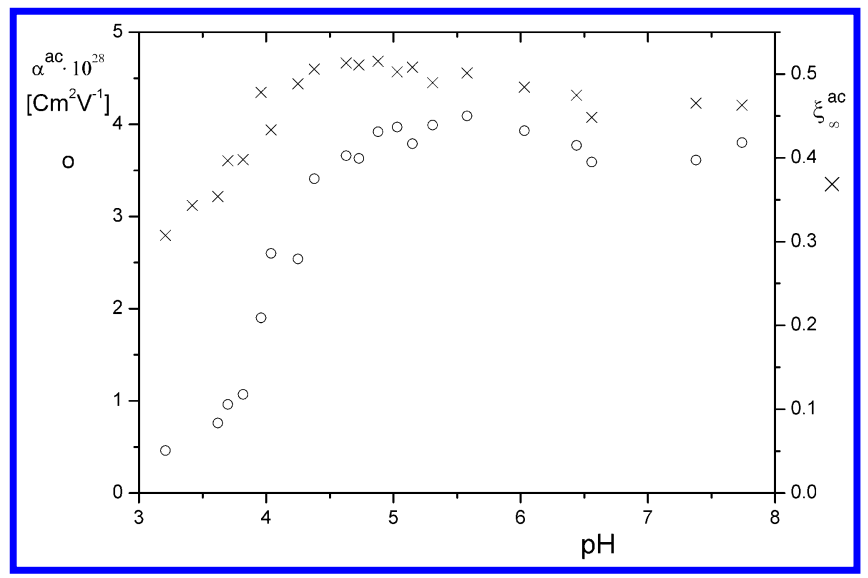

Figure 5. Polarizability, $\alpha^{\mathrm{ac}}$, and limiting value of the dichroism, $\xi_{\infty}^{\mathrm{ac}}$, of bacteriorhodopsin, determined under ac pulses, as a function of the $\mathrm{pH}\left(20^{\circ} \mathrm{C}, 1 \mathrm{mM} \mathrm{NaClO}, 200 \mu \mathrm{M} \mathrm{CaClO}_{4}\right.$, and $1 \mathrm{mM}$ Tris, cacodylate, or acetate in the different $\mathrm{pH}$ ranges; see Materials and Methods).

4). The $\mu$ values are constant in the $\mathrm{pH}$ range from 8 to 6.5 , decrease by about $50 \%$ in the $\mathrm{pH}$ range from 6.5 to 4.9 , and finally increase again below pH 4.9 (cf. Figure 4). These data demonstrate a clear minimum of the permanent dipole moment at $\mathrm{pH} 4.9$ but again do not show any approach of the dipole moment to zero. The limiting value of the dichroism, $\xi_{\infty}^{\mathrm{dc}}$, shows a maximum at $\mathrm{pH} 5.5$ and a minimum at $\mathrm{pH}$ 4.9.

AC Dichroism. In addition to dc measurements, all of the samples were characterized by parallel ac measurements. Because the dichroism induced by ac pulses approaches saturation already at relatively low electric field strengths, the limiting value, $\xi_{\infty}^{\mathrm{ac}}$, can be determined at a much higher accuracy than by dc pulses (cf. Figure 3 ). In contrast to the complex $\mathrm{pH}$ dependence found in the dc measurements, the $\xi_{\infty}^{\mathrm{ac}}$ values increase slightly in the $\mathrm{pH}$ range from 8 to 4.5 and can be considered as almost constant (cf. Figure 5). The ac measurements indicate that the global structure of the bacteriorhodopsin disks and the orientation of the retinal chromophore remain almost unaffected in the $\mathrm{pH}$ range from 8 to 4.5 . Thus, the changes indicated by the dc measurements must be attributed to changes of the permanent dipole moment.

Below $\mathrm{pH} 4.5$, there is a clear decrease of the $\xi_{\infty}^{\mathrm{ac}}$ values and also a strong decrease of the polarizability (cf. Figure 5). The polarizability indicates the existence of an ion atmosphere in the plane of the bacteriorhodopsin disks. Because the polariz- 


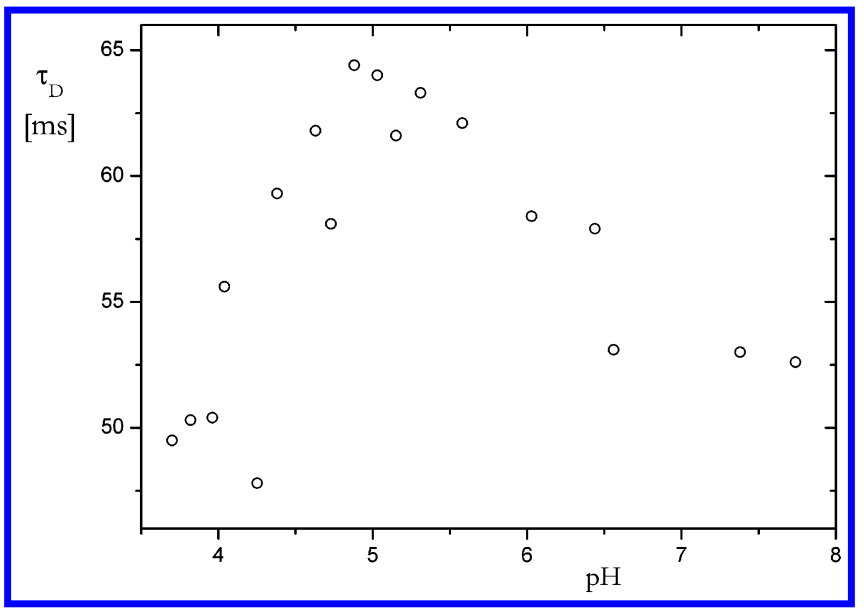

Figure 6. Dichroism decay time constant, $\tau_{\mathrm{D}}$, of bacteriorhodopsin, evaluated from data measured after termination of ac pulses, as a function of the $\mathrm{pH}\left(20^{\circ} \mathrm{C}, 1 \mathrm{mM} \mathrm{NaClO}_{4}, 200 \mu \mathrm{M} \mathrm{CaClO}_{4}\right.$, and $1 \mathrm{mM}$ Tris, cacodylate, or acetate in the different $\mathrm{pH}$ ranges; see Materials and Methods).

ability decreases to almost zero at $\mathrm{pH} 3$, it must be concluded that this ion atmosphere is almost completely extinguished in this $\mathrm{pH}$ range. The main contribution to the ion atmosphere is expected to result from the phosphate groups of lipid residues, and thus, it is likely that the phosphates are protonated in this $\mathrm{pH}$ range.

The dichroism decay time constants $\tau_{\mathrm{D}}$ are very useful as a measure for the dimensions of the bacteriorhodopsin disks according to

$$
d=\sqrt[3]{\frac{9 k T}{2 \eta} \tau_{\mathrm{D}}}
$$

where $d$ is the diameter of the disks, $k T$ is the thermal energy, and $\eta$ is the viscosity of the solvent. ${ }^{20}$ An accurate representation of the dichroism decay curves obtained for the bacteriorhodopsin preparation used in the present investigation requires more than a single exponential, indicating a distribution of disk sizes. For simplicity, the time constants $\tau_{\mathrm{D}}$ obtained from singleexponential fits are used here as a measure for the average disk size. These time constants show a slight biphasic dependence on $\mathrm{pH}$ (cf. Figure 6 ) with a maximum of $\tau_{\mathrm{D}}$ at $\mathrm{pH} \approx 5$, indicating a maximum of the disk dimensions at this $\mathrm{pH}$. The dichroism decay time $\tau_{\mathrm{D}} \approx 55 \mathrm{~ms}$ at $\mathrm{pH} 7$ corresponds to a diameter $d \approx$ $1 \mu \mathrm{m}$. When an area per bacteriorhodopsin monomer of 11.5 $\mathrm{nm}^{2}$ is used, the number of monomers per disk is $6.8 \times 10^{4}$. Based on the dipole moment for the disk, $12 \times 10^{-24} \mathrm{C} \mathrm{m}$ at $\mathrm{pH} 7$, the dipole moment for the monomer is $1.8 \times 10^{-28} \mathrm{C} \mathrm{m}$ (53 D), close to values reported previously. ${ }^{15}$

Dipole Calculated from Crystal Structure. The analysis of the experimental results may be supported by simple calculations of the dipole moment of bacteriorhodopsin using the known crystal structure. These calculations according to the procedure of Antosiewicz and Porschke ${ }^{21}$ are based on the standard $\mathrm{p} K$ values of protonatable side chains of amino acids and do not consider electrostatic coupling. Previous examples demonstrated that the dipole moments resulting from these simple calculations are surprisingly close to experimental dipole moments. ${ }^{21,22}$ It is well-known that electrostatic coupling usually induces strong changes of individual $\mathrm{p} K$ values. These changes in individual $\mathrm{p} K$ values compensate each other to a large extent such that the overall charge distribution determining the dipole moment appears to be affected to a much smaller degree. The dipole moment $\mu_{\mathrm{c}}$ calculated in the transmembrane direction

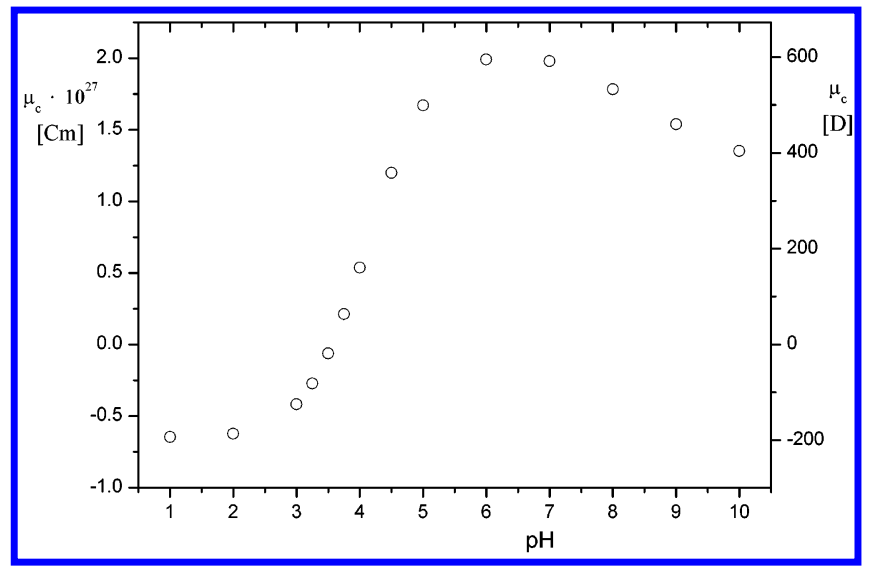

Figure 7. Component of the dipole moment, $\mu_{\mathrm{c}}$, in the transmembrane direction calculated from the crystal structure of bacteriorhodopsin (1cwq.pdb; ref 23) at different $\mathrm{pH}$ values. Calculation was performed according to the method described by Antosiewicz and Porschke. ${ }^{21}$ At $\mathrm{pH}>3.5$, the dipole is directed from the intra- to the extracellular space, represented by a positive sign; at $\mathrm{pH}<3.5$, the dipole is in the opposite direction, represented by a negative sign.

(cf. Figure 7) shows a maximum at $\mathrm{pH} \mathrm{6-7,} \mathrm{decreases} \mathrm{to} \mathrm{zero}$ at $\mathrm{pH} \approx 3.5$, and arrives at a plateau in the opposite direction at $\mathrm{pH} 1-2$. The crystal structure used for this calculation (1cwq.pdb ${ }^{23}$ ) does not include some terminal residues. When these residues are considered approximately, the resulting dipole at $\mathrm{pH} 7$ is higher by about $6.7 \times 10^{-28} \mathrm{C} \mathrm{m}(200 \mathrm{D})$.

Test of Dipole Reversal by pH and Field Jump Experiments. If a permanent dipole moment is in a stationary state of alignment due to application of an external electric field and if the direction of this permanent dipole is reverted because of a change of $\mathrm{pH}$, a dichroism signal should appear corresponding to that induced by reversal of the vector of the external electric field. Thus, a transient should appear with a characteristic dip in the dichroism. ${ }^{24}$ If the direction of the dipole is not reverted, the $\mathrm{pH}$ jump should not affect the dichroism signal, except for an eventual relaxation to a changed dichroism level, but in any case without a dip.

In the first step of the experiments, an electric field pulse was applied, inducing a stationary degree of dichroism. During the time period with a stationary level of dichroism, a light pulse was applied, which induced a fast change of the bacteriorhodopsin absorbance. When the membrane suspension contained $o$-nitrobenzaldehyde, the light pulse induced not only the fast absorbance change of bacteriorhodopsin but also a $\mathrm{pH}$ jump. The measured optical signal was clearly dependent on the start and end $\mathrm{pH}$. When the start $\mathrm{pH}$ was in the range around 8 and, thus, the end $\mathrm{pH}$ remained above the $\mathrm{pH}$ range of dipole reversal, there was no indication of a special transient. An equivalent result was obtained when the start $\mathrm{pH}$ was below the transition range. However, a clear dip in the transmitted light, revealing a dip in the dichroism, was observed when the $\mathrm{pH}$ jumped over the reversal range around $\mathrm{pH} 5$ (cf. Figure 8). Thus, the combined $\mathrm{pH}$ and field jump experiments confirmed the conclusion that the permanent dipole moment of bacteriorhodopsin is reverted. The reversal $\mathrm{pH}$ may be determined approximately from dip amplitudes measured at different start $\mathrm{pH}$ values. When the dip amplitude is plotted as a function of the $\mathrm{pH}$ value at the center of the jumps $[($ start $\mathrm{pH}+$ end $\mathrm{pH}) /$ 2], a clear maximum is observed at pH 5 (cf. Figure 9). Thus, the direction of the dipole moment is reverted at $\mathrm{pH} 5$, in agreement with the data and the conclusions presented above. 


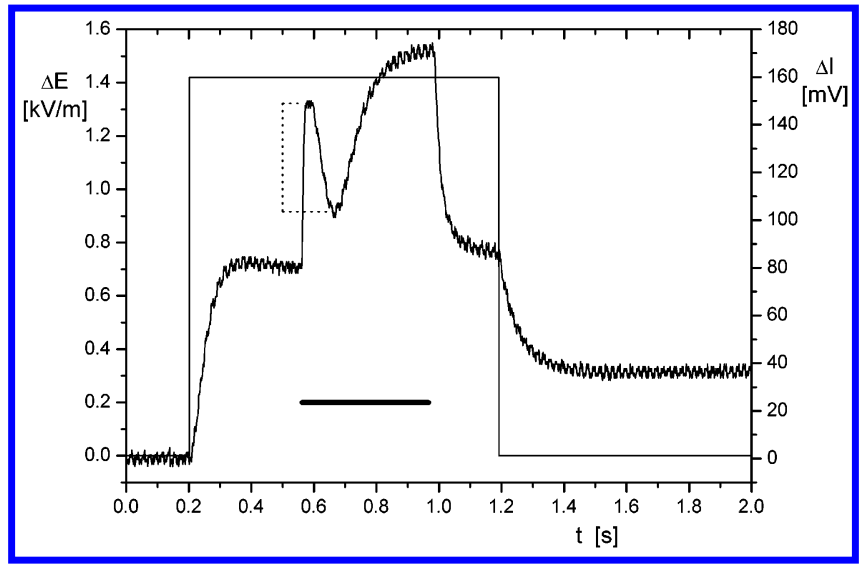

Figure 8. $\mathrm{pH}$ and field jump experiment: change of light intensity, $\Delta I$ (line with noise, right scale), as a function of time $t$; the continuous thin line (without noise) shows the electric field pulse, $\Delta E$ (left scale). The bar (thick line) shows the time period of irradiation at wavelengths $300-350 \mathrm{~nm}$. The dotted line illustrates the amplitude of the dip. Experimental conditions were $3.76 \mu \mathrm{M}$ bacteriorhodopsin, $1 \mathrm{mM}$ $o$-nitrobenzaldehyde, $\mathrm{pH}=6.26$ before light pulse, $\mathrm{pH} \approx 4.3$ after light pulse, $20{ }^{\circ} \mathrm{C}, 1 \mathrm{mM} \mathrm{NaClO}$, and $200 \mu \mathrm{M} \mathrm{CaClO}_{4}$.

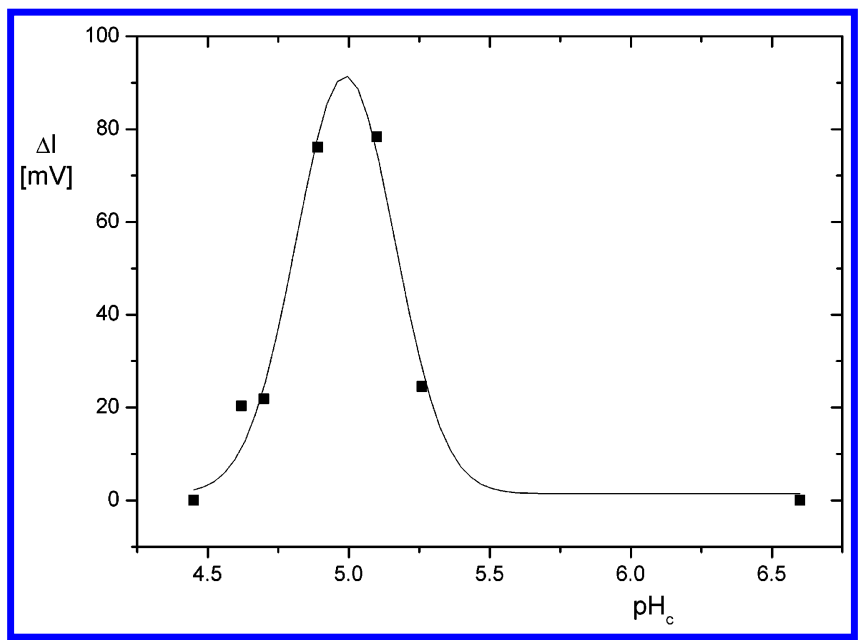

Figure 9. Dip amplitudes, $\Delta I$, observed in $\mathrm{pH}$ and field jump experiments as a function of the $\mathrm{pH}$ values, $\mathrm{pH}_{\mathrm{c}}$, at the centers of the $\mathrm{pH}$ jumps. Experimental conditions were $3.0 \mu \mathrm{M}$ bacteriorhodopsin in $1 \mathrm{mM} \mathrm{NaClO}_{4}, 200 \mu \mathrm{M} \mathrm{CaClO}_{4}$, and $1 \mathrm{mM} o$-nitrobenzaldehyde at 20 ${ }^{\circ} \mathrm{C}$. The intensity of the irradiated light pulse was $\sim 50 \%$ of that used in Figure 8, inducing an average $\mathrm{pH}$ jump by $1 \mathrm{pH}$ unit. The continuous line is a fit by a Gaussian centered at $\mathrm{pH} 5$.

\section{Discussion}

Proton pumping requires controlled changes in the protonation state of functional groups in bacteriorhodopsin, and thus, the $\mathrm{pH}$ dependence of these groups is of special interest. A remarkable $\mathrm{pH}$ dependence has been found by Barabas et al. ${ }^{8}$ and Mostafa et al. ${ }^{14}$ using combined electrooptical and photoelectric measurements, which indicate a reversal in the direction of the permanent dipole moment at $\mathrm{pH}<6$. Because of the potential interest of this result for proton pumping, we have tried to find independent evidence for dipole reversal by measurements of the stationary dichroism. If the direction of the dipole is reverted, the electric dichroism measured in the permanent dipole regime should get close to zero in the $\mathrm{pH}$ range of dipole reversal. Because of the close spacing of our measurements on the $\mathrm{pH}$ scale, any approach of the dichroism to zero should have been detected.

However, a zero dichroism at the point of dipole reversal may be expected only for the simplest scenario. Our data demonstrate different contributions to the overall dipole moment, which can be identified from the $\mathrm{pH}$ dependences of different experimental parameters. The assignment of effects contributing to the experimental results should be started from the results obtained by ac field pulses because these results are not affected by the complex $\mathrm{pH}$ dependence of the permanent dipole moment.

AC Data. First, we have to check a potential $\mathrm{pH}$ dependence of the global disk structure. A direct measure for the global structure is provided by dichroism decay time constants, $\tau_{\mathrm{D}}$, reflecting overall rotational diffusion of the disks. The data in Figure 6 demonstrate that there is a small but clearly detectable $\mathrm{pH}$ dependence of the global structure in the range between $\mathrm{pH} 8$ and 4. A maximum of the $\tau_{\mathrm{D}}$ values at $\mathrm{pH} 5$ indicates that the dimensions of the disks are maximal at this $\mathrm{pH}$ and that the dimensions decrease both at neutral and at more acidic $\mathrm{pH}$ values. Dimensions of disks may be changed by bending, depending on the charge density on the membrane surfaces. Apparently the charge density is higher on one side at neutral $\mathrm{pH}$ and on the other side at acidic $\mathrm{pH}$. Electrostatic repulsion directs the surface with the higher charge density toward the convex side of bent disks. Thus, the present results indicate $\mathrm{pH}-$ induced reversal of the bending direction: at neutral $\mathrm{pH}$, the disks are bent toward one side and at acidic $\mathrm{pH}<5$ toward the other side.

The bending model may also be used to explain part of the $\mathrm{pH}$ dependence of the limiting value $\xi_{\infty}^{\mathrm{ac}}$ of the ac dichroism (Figure 5), which shows a small maximum in the $\mathrm{pH}$ range around 5. This effect must be expected if the disks are straight at $\mathrm{pH} 5$ and bent at both $\mathrm{pH}>5$ and $<5$. Bending and its effect on the dichroism and the polarizability has been discussed already by Mostafa et al. ${ }^{14}$ The present conclusion is mainly based on time constants of rotational diffusion, providing more direct evidence than the dichroism or the polarizability. Mostafa et al. used a buffer without added bivalent ions, and thus, the membrane is converted from the purple to the blue form at a less acidic $\mathrm{pH}$ under their experimental conditions. This seems to be the source of a difference in the $\mathrm{pH}$ dependence at $\mathrm{pH}<$ 5. The effects due to bending are relatively small, whereas the effects due to the purple to blue transition are large.

The polarizability, $\alpha^{\text {ac }}$, decreases strongly at $\mathrm{pH}<4.5$ (Figure 5 ), which may not be attributed to the relatively small changes resulting from disk bending and also not yet to the purple to blue transition occurring at a more acidic $\mathrm{pH}$ under the present experimental conditions. The polarizability is due to the ion atmosphere around the disks, which is mainly associated with the phosphate groups of the lipid residues. The "interfacial" $\mathrm{p} K$ value of these phosphate groups in membranes ${ }^{25}$ at a high charge density and at a relatively low ionic strength is expected to be around 4. The $\mathrm{p} K$ shift of the phospholipid headgroups in bacteriorhodopsin may be estimated on the basis of the electrostatic double layer theory using the equation ${ }^{26}$

$$
\Delta \mathrm{p} K=(2 / \ln 10) \operatorname{arcsinh}\left(\sigma_{\mathrm{c}} / \sqrt{8000 \epsilon \epsilon_{0} R T c_{\mathrm{m}}}\right)
$$

where $\sigma_{\mathrm{c}}$ is the surface charge density at the center of titration, $\epsilon$ is the interfacial dielectric constant, $\epsilon_{0}$ is the absolute dielelectric permittivity, $R$ is the gas constant, $T$ is the absolute temperature, and $c_{\mathrm{m}}$ is the ionic strength in molar units. The total number of negative charges resulting from the lipid headgroups per protein monomer is estimated to be $\sim 16$ (cf. Jonas et al. ${ }^{27}$ ), providing an average surface charge density of $0.056 \mathrm{C} \mathrm{m}^{-2}$ at the center of titration. Using $\epsilon=32$ (Fernandez and Fromherz ${ }^{28}$ ) and $c_{\mathrm{m}}=2 \times 10^{-3} \mathrm{M}$ for the ionic strength 
of the buffer provides a shift $\Delta p \mathrm{~K}=3.1$. Based on the monomer $\mathrm{p} K$ value 1 , the predicted interfacial $\mathrm{p} K$ is 4.1 , in satisfactory agreement with the experimental data. Thus, the strong decrease of the polarizability with an apparent $\mathrm{p} K$ of 4 is due to protonation of phosphate groups of lipid residues and loss of the ion atmosphere.

DC Data. Because the ac data demonstrate that changes of the global disk structure remain relatively small, most of the special effects indicated by the dc dichroism must be attributed to changes in the dipole moment. The minimum value of the dichroism, $\xi_{\mathrm{min}}^{\mathrm{dc}}$, has been selected as indicator because it can be read at a high accuracy and is directly related to the magnitude of the permanent dipole moment. $\xi_{\min }^{\mathrm{dc}}$ shows a $\lambda$ point at $\mathrm{pH} 4.9$ but does not approach zero (Figure 2). The dependence of $\xi_{\mathrm{min}}^{\mathrm{dc}}$ on $\mathrm{pH}$ is converted to the conventional form of a standard titration curve when the sign of $\xi_{\min }^{\mathrm{dc}}$ values at $\mathrm{pH}<4.9$ is inverted. These data indicate that the direction of the permanent dipole is reverted at $\mathrm{pH} 4.9$.

The analysis of the dc dichroism data by the orientation function provides more detailed information, although the accuracy of the resulting parameters is not optimal because the orientation function can only be used to represent experimental data at low field strengths. The deviations of the experimental data from the theoretical expectation are probably mainly due to a field-induced reaction described previously. ${ }^{15,18,19}$ Other factors contributing to deviations may be saturation of the polarizability and also some size distribution of the membrane fragments. Despite these problems, the parameters obtained from the low-field data should be useful as a reasonable approximation. The permanent dipole moment obtained from this analysis is constant in the $\mathrm{pH}$ range from 8 to 6.5 , decreases between 6.5 and 5, and increases again between pH 5 and 4 (Figure 4). At the minimum level observed around $\mathrm{pH} 5$, the dipole moment is reduced to $50 \%$ of the value found at neutral $\mathrm{pH}$ and is far away from the zero level. It is remarkable that the limiting dc dichroism, $\xi_{\infty}^{\mathrm{dc}}$, shows a minimum at $\mathrm{pH} 4.9$, whereas the limiting ac dichroism, $\xi_{\infty}^{\mathrm{ac}}$, determined in parallel measurements on the same samples, remains at the high level characteristic of native bacteriorhodopsin. Thus, the minimum of $\xi_{\infty}^{\mathrm{dc}}$ must be explained by some special property of the permanent dipole.

Dipole Components of Purple Membranes. Our data seem to be in internal contradiction, but this problem may be resolved by a model for bacteriorhodopsin disks with two components in addition to the standard protein dipole. The interpretation starts from the assignment that the static dipole moment of bacteriorhodopsin disks is zero at $\mathrm{pH}$ 4.9. The experimental observation of a residual permanent dipole moment at this $\mathrm{pH}$ is attributed to a fluctuating moment, probably resulting from bending fluctuations. These fluctuations are associated with relatively small dipole moments for part of the disks, but some disks undergo large fluctuations resulting in large dipole moments, which are detected in the present experiments. This explains the clear decrease of the dc limiting dichroism at $\mathrm{pH}$ 4.9 because disks without large fluctuations are not oriented by the electric field pulses. Obviously, fluctuations on the local protein level compensate each other at a high probability, and thus, fluctuations on the global level such as bending of the membrane fragments are required.

The calculations of the dipole moment for the protein predict reversal at a lower $\mathrm{pH}$ value than that observed for the disks in the experiments. This difference of $\sim 1.4 \mathrm{pH}$ units suggests the existence of another dipole component. An additional dipole component is also indicated by the fact that the measured dipole moment per monomer unit at $\mathrm{pH} 7$ is $\sim 53 \mathrm{D}$, while the calculated protein dipole is more than an order of magnitude higher $(\sim 600 \mathrm{D})$. The large difference indicates the existence of a high dipole component directed opposite to that of the protein. A component in this direction also explains the shift of the reversal $\mathrm{pH}$. Finally the experimental data indicate a higher dipole moment at $\mathrm{pH} 4$ than at $\mathrm{pH} 7$, at which the calculated protein dipole is close to zero and, thus, the additional component is almost uncompensated. In summary, all of the experimental observations indicate the existence of this additional dipole component. The most likely source of this component is a nonsymmetric distribution of charges on lipid residues. According to the literature, there are up to 10 lipid molecules ${ }^{3}$ with charged headgroups per protein monomer. The structure model 2 brd.pdb ${ }^{29}$ shows five lipid headgroups at each side of the membrane. However, all of the headgroups are disordered. It is possible that substitution and charge states of these headgroups are different and, thus, the charges need not be distributed symmetrically.

The magnitude of the additional component may be estimated by combination of experimental and calculated dipole moments. All of the dipole moments mentioned below are given in the transmembrane direction. The direction from the intra- to the extracellular space is denoted by a $(+)$ sign, whereas the opposite direction is denoted by a $(-)$ sign. Starting from the experimental dipole per monomer, $-61 \mathrm{D}$ at $\mathrm{pH} 4$, which is already opposite to the direction of the protein dipole and the calculated dipole of the protein at this $\mathrm{pH},+150 \mathrm{D}$, we get a value for the additional component of $-211 \mathrm{D}$. If this component is attributed to lipid phosphates, which are protonated at $\mathrm{pH} 4$ to the extent of $\sim 50 \%$ (Figure 5), the total additional dipole component at $\mathrm{pH} 7$, at which these residues are not protonated, is approximately $-420 \mathrm{D}$. Combination of this value with the experimental dipole moment, $53 \mathrm{D}$, at $\mathrm{pH} 7$ provides a value of $\sim 470 \mathrm{D}$ for the protein at $\mathrm{pH} 7$, which is now in the order of magnitude expected from the calculation based on the crystal structure. Obviously, the present estimation must be regarded as a first approximation with a relatively large uncertainty. Despite the remaining uncertainty about the exact magnitudes of the different components, the available data provide clear evidence for the existence of an additional dipole component.

For comparison, it should be useful to estimate the magnitude of a dipole component resulting from a single charge on one side of the disk. In the ideal limit case of charges on the surface of a flat membrane with a width of $6 \mathrm{~nm}$, the dipole component per monomer would be $1 / 2\left(6 \times 10^{-9}\right) e=4.81 \times 10^{-28} \mathrm{C} \mathrm{m}$ ( $\equiv 144 \mathrm{D} ; e$ is the elementary charge and the factor $1 / 2$ results from the fact that there is no positive counter-charge on the opposite side of the membrane). However, the disks are not flat, and thus, the distance factor is different from $6 \times 10^{-9} \mathrm{~m}$. A reasonable prediction of the charge asymmetry requires more extensive model calculations.

Membrane Stability and Function. The permanent dipole moment of purple membrane fragments is extremely high, corresponding to $1.2 \times 10^{-23} \mathrm{C} \mathrm{m}\left(\equiv 3.6 \times 10^{6} \mathrm{D}\right)$ for disks with an average diameter of $1 \mu \mathrm{m}$. Our results indicate that this dipole would be much higher by about a factor of 10 , if it would be without compensation. Apparently compensation of the large protein dipole within the disk structure is essential for its stability. The existence of the dipole moment is clearly related to the direction of proton transport by its vector property. The dipole supports attraction of protons at the cytoplasmic side of the membrane and repulsion of protons at the extracellular side. The function of the dipole is illustrated by the $\mathrm{pH}$ dependence 
of light-induced stationary $\mathrm{pH}$ changes ${ }^{30}$ observed in suspensions of bacteriorhodopsin disks. Illumination of bacteriorhodopsin leads to proton release at $\mathrm{pH}>5$ and to proton uptake at $\mathrm{pH}<$ 5. Thus, the change from proton release to proton uptake is found at a $\mathrm{pH}$ value very close to that of dipole reversal. These data indicate that the dipole moment supports proton transport. Certainly the essential step for pumping activity is the lightinduced $\mathrm{p} K$ shift of the Schiff base, together with a relay function resulting from controlled reorientation of residues. This process is supported by the vectorial character of the dipole.

Acknowledgment. The authors are indebted to Dr. J. Tittor for providing Halobacterium salinarum S9 and to Jürgen Wawrzinek for technical assistance.

\section{References and Notes}

(1) Stoeckenius, W.; Bogomolni, R. A. Annu. Rev. Biochem. 1982, $52,587-616$. 515.

(2) Ottolenghi, M., Sheves, M., Eds. Isr. J. Chem. 1995, 35, 193-

(3) Haupts, U.; Tittor, J.; Oesterhelt, D. Annu. Rev. Biophvs. Biomol. Struct. 1999, 28, 367-399.

(4) Lanyi, J. K., Ed. Biochim. Biophvs. Acta 2000, 1460, 1-239.

(5) Keszthelyi, L. Biochim. Biophys. Acta 1980, 598, 429-436.

(6) Kimura, Y.; Ikegami, A.; Ohno, K.; Saigo, S.; Takeuchi, Y. Photochem. Photobiol. 1981, 33, 435-439.

(7) Kimura, Y.; Fujiwara, M.; Ikegami, A. Biophys. J. 1984, 45, 615625.

(8) Barabas, K.; Der, A.; Dancshazy, Z.; Ormos, P.; Keszthelyi, L.; Marden, M. Biophys. J. 1983, 43, 5-11.

(9) Kahn, L. D.; Tu, S. I. Biopolymers 1984, 23, 707-718.
(10) Stoylov, S. P.; Todorov, G.; Zhivkov, A. Bioelectrochem. Bioenerg. 1984, 12, 49-55.

(11) Papp, E.; Fricsovszky, G.; Meszena, G. Biophys. J. 1986, 49, 10891100 .

(12) Taneva, S. G.; Jordanova, N.; Petkanchin, I. B. Biophvs. Chem 1992, 44, 91-97.

(13) Taneva, S. G.; Todorov, G.; Petkanchin, I. B.; Stoylov, S. P. Eur. Biophvs. J. 1987, 14, 415-421.

(14) Mostafa, H. I. A.; Varo, G.; Toth-Boconadi, R.; Keszthelyi, L. Biophvs. J. 1996, 70, 468-472.

(15) Porschke, D. Biophys. J. 1996, 71, 3381-3391.

(16) Oesterhelt, D.; Stoeckenius, W. Methods Enzvmol. 1974, 31, 667670.

(17) Shah, M. J. J. Phys. Chem. 1963, 67, 2215-2219.

(18) Tsuji, K.; Neumann, E. FEBS Lett. 1981, 128, 265-268.

(19) Geibel, S.; Friedrich, T.; Ormos, P.; Wood, P. G.; Nagel, G.; Bamberg, E. Biophys. J. 2001, 81, 2059-2068.

(20) Perrin, F. J. Phys. 1934, 5, 497-511.

(21) Antosiewicz, J.; Porschke, D. Biochemistry 1989, 28, 10072-10078.

(22) Porschke, D. Biophvs. Chem. 1997, 66, 241-257.

(23) Sass, H. J.; Buldt, G.; Gessenich, R.; Hehn, D.; Neff, D. Schlesinger, R.; Berendzen, J.; Ormos, P. Nature 2000, 406, 649-653.

(24) Fredericq, E.; Houssier, C. Electric dichroism and electric birefringence; Clarendon: Oxford, U.K., 1973.

(25) Cevc, G.; Marsh, D. Phospholipid bilayers; Wiley: New York, 1987.

(26) Träuble, H.; Teubner, M.; Woolley, P.; Eibl, H. Biophvs. Chem. 1976, 4, 319-342.

(27) Jonas, R.; Koutalos, Y.; Ebrey, T. G. Photochem. Photobiol. 1990, $52,1163-1177$ 1761.

(28) Fernandez, M. S.; Fromherz, P. J. Phys. Chem. 1977, 81, 1755-

(29) Grigorieff, N.; Ceska, T. A.; Downing, K. H.; Baldwin, J. M.; Henderson, R. J. Mol. Biol. 1996, 259, 393-421.

(30) Varo, G.; Lanyi, J. K. Biochemistry 1990, 29, 6858-6865. 